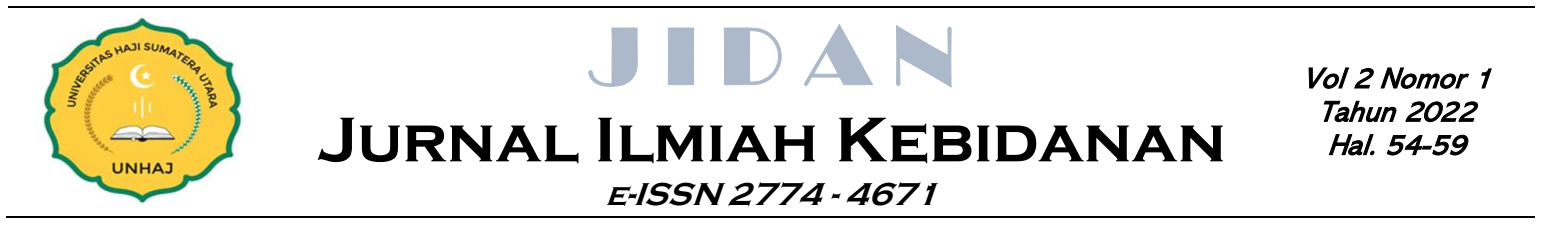

\title{
PENGARUH PENDIDIKAN KESEHATAN TERHADAP PENGETAHUAN IBU TENTANG TANDA BAHAYA KEHAMILAN DI RS MITRA MEDIKA AMPLAS
}

\author{
Devi Sagita Saragi ${ }^{1}$, Winni Juliarti Hasibuan ${ }^{2}$ \\ 1,2 Universitas Haji Sumatera Utara, Medan, Indonesia \\ Email: 1devissaragi11@gmail.com
}

\begin{abstract}
Abstrak
Kehamilan merupakan proses yang normal dan alamiah pada seorang wanita dimana dalam masa kehamilan terjadi perubahan fisik, psikologis dan sosial. Setiap kehamilan membawa risiko bagi ibu. World Health Organization (WHO) memperkirakan sekitar 15\% dari seluruh wanita hamil akan berkembang menjadi komplikasi yang berkaitan dengan kehamilannya serta mengancam jiwanya (Hani, 2015). penelitian ini bertujuan untuk mengetahui pengaruh pendidikan kesehatan terhadap pengetahuan ibu hamil tentang tanda bahaya kehamilan di Rumah Sakit Mitra Medika Amplas. Penelitian ini menggunakan metode pre experimental dengan pendekatan one group pre test-post test design. Populasi dalam penelitian yang dilakukan adalah Seluruh Ibu hamil yang memeriksakan kehamilan di Rumah Sakit Mitra Medika Amplas pada bulan April berjumlah 212 orang. Tehnik pengambilan sampel dengan menggunakan teknik Accidental sampling dengan jumlah responden 48 ibu hamil yang sesuai dengan kriteria peneliti dan mengikuti penelitian sampai selesai. Analisa data yang digunakan dalam penelitian ini adalah uji wilcoxon. Pendidikan kesehatan diberikan 1 kali selama 5 menit dengan metode ceramah, curah pendapat dan diskusi. Data pre test dan post test diambil dengan kuesioner yang telah diuji validitas dan realibilitas. Post test dilakukan 7 menit setelah pemberian pendidikan kesehatan. Data dianalisis dengan uji Wilcoxon dengan p-value $=0,000$ dan z $=5,046(\alpha=0,05)$. Hasil penelitian menunjukkan ada pengaruh pendidikan kesehatan terhadap pengetahuan ibu hamil tentang tanda bahaya kehamilan di Rumah Sakit Mitra Medika Amplas. Berdasarkan hasil penelitian, disarankan agar petugas kesehatan memberikan pendidikan kesehatan dan mengevaluasi untuk mengetahui keberhasilan pendidikan kesehatan.
\end{abstract}

Kata kunci: Pengetahuan, pendidikan kesehatan, tanda bahaya kehamilan

\begin{abstract}
Pregnancy is a normal and natural process for a woman where during pregnancy there are physical, psychological and social changes. Every pregnancy carries risks for the mother. The World Health Organization (WHO) estimates that around 15\% of all pregnant women will develop complications related to their pregnancy and threaten their lives (Hani, 2015). This study aims to determine the effect of health education on the knowledge of pregnant women about the danger signs of pregnancy at Mitra Medika Amplas Hospital. This study uses a preexperimental method with a one-group pre-test-post-test design approach. The population in this study were all pregnant women who had their pregnancy checked at Mitra Medika Amplas Hospital in April totaling 212 people. The sampling technique used was accidental sampling with 48 pregnant women as respondents who met the researcher's criteria and followed the research to completion. Analysis of the data used in this study is the Wilcoxon test. Health education is given once for 5 minutes using lecture, brainstorming and discussion methods. Pre-test and post-test data were taken with a questionnaire that had been tested for validity and reliability. The post test was carried out 7 minutes after the health education was given. Data were analyzed by Wilcoxon test with $p$-value $=0.000$ and $z=5.046(\alpha=0.05)$. The results showed that there was an effect of health education on the knowledge of pregnant women about the danger signs of pregnancy at Mitra Medika Amplas Hospital. Based on the results of the study, it is recommended that health workers provide health education and evaluate to determine the success of health education.
\end{abstract}

Keyword: Knowledge, health education, danger signs of pregnancy 


\section{JURNAL ILMIAH KEBIDANAN \\ E-ISSN 2774-4671}

Pendahuluan

Kehamilan merupakan proses yang normal dan alamiah pada seorang wanita dimana dalam masa kehamilan terjadi perubahan fisik, psikologis dan sosial. Setiap kehamilan membawa risiko bagi ibu. World Health Organization (WHO) memperkirakan sekitar 15\% dari seluruh wanita hamil akan berkembang menjadi komplikasi yang berkaitan dengan kehamilannya serta mengancam jiwanya (Hani, 2015).

World Health Organization (WHO) menyatakan bahwa pada tahun 2015 sekitar 830/harinya wanita meninggal di seluruh dunia akibat komplikasi kehamilan dan persalinan, sedangkan secara keseluruhan Angka Kematian Ibu (AKI) sebanyak 303.000/100.000 kelahiran hidup. Hampir semua kematian ibu terjadi di negara berkembang yaitu lebih dari setengah kematian terjadi di afrika Sub-sahara dan hampir di sepertiga terjadi di asia selatan. Ini masih dalam kategori tinggi karena belum mencapai target Sustainable Development Goals (SDG's) yaitu<70 per 100.000 kelahiran hidup (WHO, 2018).

Sumatera utara adalah salah satu provinsi di Indonesia, dengan AKI sebanyak 205 orang pada tahun 2017 dan terjadi sedikit penurunan pada tahun 2016 yaitu sebanyak 239 orang (Dinkes Sumut, 2017). Dari 33 kabupaten yang ada di provinsi Sumatera utara, kabupaten labuhan batu dan kabupaten deli serdang merupakan urutan pertama tertinggi dengan AKI sebanyak 15 orang (Dinkes Sumut, 2017).

Untuk mencegah risiko yang lebih berbahaya bagi ibu hamil dan janinnya, maka pengetahuan ibu tentang tanda-tanda bahaya kehamilan perlu ditingkatkan. Pengetahuan adalah hasil dari tahu, dan terjadi setelah orang melakukan penginderaan terhadap suatu objek tertentu. Penginderaan itu terjadi melalui panca indera manusia yakni indera penglihatan, pendengaran, penciuman, rasa dan raba. Sebagian besar penginderaan manusia diperoleh melalui mata dan telinga. Pengetahuan dan kognitif merupakan domain yang sangat penting dalam membentuk tindakan seseorang (over behavior) (Notoatmodjo, 2016).

Menurut Notoatmodjo (2016) pendidikan kesehatan adalah upaya persuasi atau pembelajaran kepada masyarakat agar masyarakat mau melakukan tindakan-tindakan untuk memelihara, dan meningkatkan taraf kesehatannya.

Tanda-tanda bahaya kehamilan antara lain perdarahan pervaginam, nyeri abdomen yang hebat, kurangnya gerakan janin, bengkan/oedema, penglihatan kabur, sakit kepala hebat, demam, muntah-muntah hebat, dan keluar cairan pervaginam secara tiba-tiba (Hani, 2016).

Adapun tujuan penelitian ini adalah untuk mengetahui pengaruh pendidikan kesehatan kerhadap pengetahuan ibu hamil tentang tanda bahaya kehamilan di Rumah Sakit Mitra Medika Amplas

\section{Metode Penelitian}

Jenis penelitian ini menggunakan pre experiment, dengan desain penelitian yang digunakan oleh peneliti adalah rancangan one group pre test-posttest design. Penelitian ini dilakukan di Rumah Sakit Medika Amplas dengan populasi penelitian yaitu ibu hamil yang sedang berkunjung. Teknik pengambilan sampel dalam penelitian ini adalah accidental sampling sehingga didapat responden ibu hamil sebanyak 48 orang. Data didapatkan secara langsung dengan melihat hasil kuesioner. Teknik pengumpulan data yaitu dengan membagikan kuesioner kepada responden yang kebetulan hadir, kemudian data yang terkumpul lalu diolah mulai dari editing, coding, entry data, cleaning hingga tabulating. Selanjutnya data dianalisa dengan Uji Wilcoxon.

Bagian dari metode penelitian ini berisi paparan dalam bentuk paragraf tentang disain penelitian, sumber data, teknik pengumpulan data, dan analisis peneliti sesungguhnya, dengan panjang $10-15 \%$ dari total panjang artikel. 


\section{JURNAL ILMIAH KEBIDANAN \\ E-ISSN 2774-4671}

\section{Hasil dan Pembahasan}

Tabel 1. Distribusi ibu hamil berdasarkan usia, pendidikan terakhir, paritas, usia kehamilan di Rumah Sakit Mitra Medika Amplas

\begin{tabular}{lcc}
\multicolumn{1}{c}{ Kategori } & Frekuensi (n) & Persentase (\%) \\
\hline $17-25$ Tahun & 15 & 31,25 \\
\hline $26-35$ Tahun & 27 & 56,25 \\
\hline $36-45$ Tahun & 6 & 12,5 \\
\hline Total & 48 & 100 \\
\hline Pendidikan & & 6,25 \\
\hline SD & 3 & 25 \\
\hline SMP/MTS & 12 & 41,67 \\
\hline SMA/MA & 20 & 27,08 \\
\hline PT/Akademi & 13 & 100 \\
\hline Total & 48 & 20,83 \\
\hline Paritas & & 43,75 \\
\hline Primigravida & 10 & 35,41 \\
\hline Multigravida & 21 & 100 \\
\hline Grandemultigravida & 17 & \\
\hline Total & 48 & 31,25 \\
\hline Usia kehamilan & & 47,91 \\
\hline Trimester 1 & 15 & 20,83 \\
\hline Trimester 2 & 23 & 100 \\
\hline Trimester 3 & 10 & \\
\hline Total & 48 & \\
\hline & & \\
\hline
\end{tabular}

Berdasarkan tabel di atas menunjukkan bahwa dari 48 responden karakteristik responden mayoritas responden berumur 26 - 35 tahun sebanyak 27 orang (56,25\%), memiliki pendidikan SMA sebanyak 20 orang $(41,67 \%)$, responden multigravida sebanyak 21 orang $(43,75)$, usia kehamilan responden trimester 2 , yakni sebanyak 23 orang $(47,91 \%)$.

Tabel 2. Distribusi pengetahuan ibu hamil sebelum dilakukan pendidikan kesehatan tentang tanda bahaya kehamilan di Rumah Sakit Mitra Medika Amplas

\begin{tabular}{lcc} 
Pengetahuan & Frekuensi (n) & Persentase (\%) \\
\hline Baik & 11 & 22,91 \\
\hline Cukup & 22 & 45,83 \\
\hline Kurang & 15 & 31,25 \\
\hline Total & 48 & 100
\end{tabular}

Berdasarkan tabel di atas menunjukkan bahwa pengetahuan ibu hamil tentang tanda bahaya kehamilan sebelum diberikan pendidikan kesehatan mayoritas 22 responden (45.83\%) berpengetahuan cukup.

Tabel 3. Distribusi pengetahuan ibu hamil setelah dilakukan pendidikan kesehatan tentang tanda bahaya kehamilan di Rumah Sakit Mitra Medika Amplas

\begin{tabular}{lcc} 
Pengetahuan & Frekuensi (n) & Persentase (\%) \\
\hline Baik & 27 & 56,25 \\
\hline Cukup & 18 & 37,5 \\
\hline Kurang & 3 & 6,25 \\
\hline Total & 48 & 100 \\
\hline
\end{tabular}




\section{JURNAL ILMIAH KEBIDANAN \\ E-ISSN 2774-4671}

Berdasarkan tabel di atas menunjukkan bahwa pengetahuan ibu hamil tentang tanda bahaya kehamilan sesudah diberikan pendidikan kesehatan mayoritas 27 responden $(56.25 \%)$ berpengetahuan baik.

Tabel 4. Hasil Uji Statistik Pengaruh pendidikan kesehatan terha dap pengetahuan ibu hamil tentang tanda bahaya kehamilan di Rumah Sakit Mitra Medika Amplas

\begin{tabular}{ccccccc}
$\begin{array}{l}\text { Pengetahuan ibu } \\
\text { hamil }\end{array}$ & N & Mean & Std & SE & Z & \multicolumn{2}{c}{$P$} \\
\hline Sebelum & 48 & 63,75 & 15,11 & - & $\begin{array}{c}\text { Zhitung } \\
5,046>\end{array}$ & $\begin{array}{c}P \\
0,000<\end{array}$ \\
\hline Sesudah & 48 & 74,375 & 12,70 & - & Ztabel 2,14 & 0,05
\end{tabular}

Berdasarkan tabel 4.4 terlihat hasil uji statistic menggunakan Wilcoxon Sign Rank Test menunjukkan bahwa terdapat perbedaan nilai mean sebelum intervensi dan sesudah intervensi, nilai mean sebelum intervensi menunjukkan angka 64,93 sedangkan sesudah intervensi meningkat menjadi 73,31. Dan nilai Std. Deviation sebelum intervensi 13,26 dan sesudah intervensi 11,57. Pada asym.sig (2-Tailed) menunjukkan angka $0,000<0,05$. Zhitung 5,046>Ztabel maka H0 ditolak dan H1 diterima atau ada pengaruh pendidikan kesehatan terhadap pengetahuan ibu hamil tentang tanda bahaya kehamilan di Rumah Sakit Mitra Medika Amplas.

\section{Pembahasan}

Berdasarkan hasil penelitian pretest pada ibu hamil menunjukkan bahwa mayoritas ibu berpengetahuan kurang sebanyak 22 responden (45.83\%). Pada saat mengisi kuesioner, ibu hamil ada yang mengetahui tentang tanda bahaya kehamilan dan sebagian besar hanya memahami bahwa tanda bahaya kehamilan adalah suatu komplikasi yang dapat membahayakan janin.

Pengetahuan ibu hamil dapat dipengaruhi oleh beberapa hal seperti usia, pengalaman dan pendidikan. Ini sesuai dengan penelitian Aminingsih yang menyatakan bahwa semakin matang usia maka akan semakin bersikap dewasa sehingga mempermudah penerimaan informasi. Usia responden yang cukup akan memiliki tingkat pengetahuan yang semakin baik (Aminingsih et.al 2015). Mubarak (2013) juga menyatakan makin tinggi pendidikan seseorang maka semakin mudah dalam menerima informasi, dan semakin banyak pengetahuan yang di peroleh.

Setelah diberikan pendidikan kesehatan dan diberikan jeda waktu selama 5 menit diperoleh hasil mayoritas berpengetahuan baik sebanyak 27 orang $(56,25 \%)$. Wenas menyatakan peningkatan pengetahuan selain dipengaruhi oleh peran petugas kesehatan dalam pemberian informasi juga dipengaruhi pengalaman, keadaan sosial budaya dan perolehan informasi (Wenas et.al, 2014). Hal ini serupa dengan penelitian yang dilakukan Ningtyas, Muslihah, (2018) dengan hasil adanya peningkatan pengetahuan dengan metode ceramah.

Perubahan tingkat pengetahuan ibu hamil dapat dipengaruhi oleh karakteristik tiap responden. Keberhasilan pendidikan kesehatan ditunjang oleh beberapa faktor diantaranya metode yang digunakan, media dan cara penyampaian. Penelitian ini menggunakan metode diskusi, media yang digunakan kuesioner dan leaflet. keberhasilan metode diskusi dipengaruhi oleh kemampuan peneliti dengan menguasai materi dan mampu menyampaikan sesuai dengan sasaran. Selain itu jugadi dukung dengan media yang dipergunakan (Machfoedz \& Suryani 2015).

Penelitian ini juga menggunakan leaflet. Leaflet dapat disimpan, praktis, dan dapat dipelajari kapanpun responden mau (machfoedz \& suryani 2015). Hal ini sesuai dengan penelitian Umah yang menggunakan media leaflet dan flip chat yang keduanya berguna membantu dalam perberian pendidikan kesehatan dengan fungsi sebagai objek sehingga responden mendapatkan stimulus dari media dan terjadi perekaman oleh panca indra kemudian menjadikan responden tahu apa yang disampaikan oleh peneliti (Umah et.at, 2014). 


\section{JURNAL ILMIAH KEBIDANAN \\ E-ISSN 2774 - 4671}

Hasil penelitian ini menunjukan bahwa ada pengaruh pendidikan kesehatan terhadap skor pengetahuan ibu hamil tentang tanda bahaya kehamilan. Pada penelitian ini terjadi kenaikan pengetahuan sebesar rata-rata $8(65,31$ menjadi 73,95$)$. Dari 48 responden, 16 orang mengalami peningkatan pengetahuan dari rendah menjadi sedang atau baik dan pengetahuan sedang menjadi baik, sedangkan 3 lainnya tidak mengalami perubahan tingkatan pengetahuan berupa pengetahuan sedang dan pengetahuan baik namun terjadi peningkatan skor.

Dari hasil penelitian yang ada serta di dukung oleh penelitian sebelumnya peneliti berpendapat bahwa peningkatan pengetahuan responden disebabkan oleh pemberian informasi atau materi yang dilakukan secara 2 kali pertemuan dengan mengisi kuesioner, diskusi dan evaluasi (evaluasi sejauh mana pemahaman ibu dengan permainan memilih jawaban yang benar). Peneliti juga berpendapat bahwa tingkat pengetahuan seseorang akan bertambah bila sudah mendapatkan pendidikan dan informasi kesehatan sehingga cepat dalam pengambilan keputusan.

\section{Kesimpulan}

Berdasarkan hasil penelitian yang dilakukan di Rumah Sakit Mitra Medika Amplas kepada ibu hamil, dapat disimpulkan bahwa pengetahuan ibu hamil tentang tanda bahaya kehamilan sebelum diberikan pendidikan kesehatan mayoritas responden berpengetahuan cukup sedangkan sesudah diberikan pendidikan kesehatan mayoritas berpengetahuan baik. Diketahui terdapat pengaruh pendidikan kesehatan terhadap pengetahuan ibu hamil tentang tanda bahaya kehamilan di Rumah Sakit Mitra Medika Amplas (nilai $\mathrm{p}=0,000$ ).

\section{Referensi}

Aminingsih, S, Warsini,\& Padmiati Umi (2013). Pengaruh pendidikan kesehatan terhadap pengetahuan dan keterampilan dalam perawatan payudara pada ibu postpartum di RS Oen Surakarta.

KOSALA. JIK.Vol. 1. No.2.2013

Arikunto, 2010. Prosedur Penelitian suatu pendekatan praktek. Jakarta : Rineke Cipta

Budiman,Ranti L, Gayan A TD.(2014). Hubungan karakteristik ibu hamil dengan pengetahuan tentang tanda bahaya kehamilan di desa kertajaya kecamatan tanggeung kabupaten cianjur tahun 2014. Jurnal Kesehatan periangan, Vol. 1 No.3 (september 2014)

Fitriani, S. (2015). Promosi Kesehatan. Yogyakarta : Graha Ilmu

Hidayat, 2014. Metode Penelitian Keperawatan dan Teknik Analisis Data. Jakarta : Salemba Medika, 2014.

Kumalasari, I \& Iwan, A. 2012. Kesehatan Reproduksi untuk Mahasiswa Kebidanan dan Keperawatan. Jakarta : Salemba Medika.

Kementerian Kesehatan RI. 2017,Profil kesehatan Sumatera Utara 2017 from:http://www.depkes.go.id/resources/download/profil/PROFIL_KES_PROVINSI_2014/02_Su mut_2014.pdf Accessed 10 April 2018

Mahadewi, 2016. Hubungan Pengetahuan Tentang Tanda Bahaya Kehamilan dan Dukungan Keluarga Dengan Kepatuhan Kunjungan Antenatal Care (ANC). Serang

Machfoedz I, Suryani E.(2015).Pendidikan Kesehatan Bagian dari Promosi Kesehatan. Yogyakarta: Fitramaya

Manuaba, IGB. 2015. Ilmu Kebidanan Penyakit Kandungan dan Keluarga Berencana Untuk Pendidikan Bidan. Jakarta: EGC.

Maulana, H.Promosi Kesehatan.Jakarta:EGC;2015.

Maryunani, 2016.Asuhan Kegawatdaruratan Dalam Kebidanan. Jakarta: Trans Info Media

Mubarak, W I, Chayatin N, (2014). Promosi kesehatan sebuah pengantar belajar mengajar dalam pendidikan.yogyakarta: Graha Ilmu

Notoatmodjo, 2017. Promosi Kesehatan Teori dan Perilaku Kesehatan. Jakarta : Rineke Cipta , 2016. Ilmu Kesehatan Masyarakat, Cetakan Kedua, Jakarta : Rineka Cipta. 


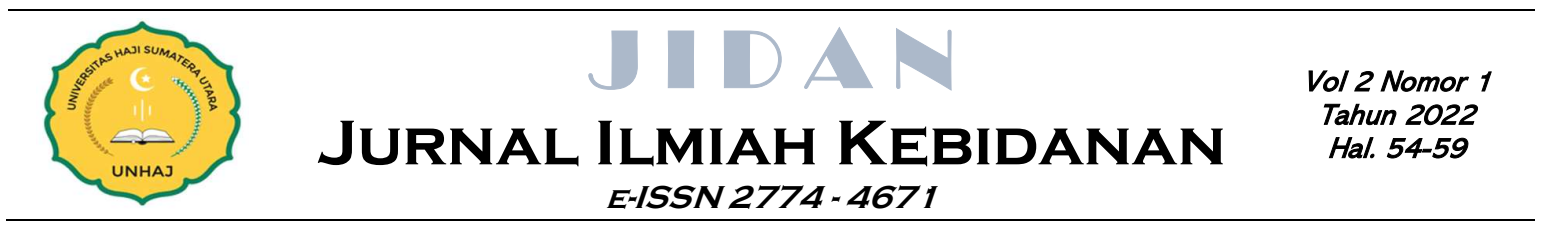

Nursalam, \& Efendi 2014. Pendidikan Dalam Keperawatan : Aplikasi dalam praktik keperawatan profesional edisi 4. Jakarta : Salemba Medika

Nursalam, 2016. Konsep dan penerapan Metedologi Penelitian Keperawatan, Salemba Medika : Jakarta

Prawiroharjdo S. 2017. Ilmu Kebidanan. Jakarta : Bina Pustaka

Rukiyah, A.Y. dan Lia Y. 2016. Asuhan Kebidanan VI (Patologi Kebidanan). Cetakan Kedua. Jakarta : Trans Info Media

Saifuddin, Abdul Bari, 2017. Pelayanan kesehatan Maternal dan Neonatal, Yayasan Bina Pustaka Sarwono Prawirohardjo, Jakarta

Sulistyawati. 2015. Asuhan Kebidanan Kehamilan. Salemba Medika. Jakarta

Sunarti, E. 2015. Mengasuh dengan hati. Jakarta

Umah Khoiroh, Lina M.R, Zulfah Rizqiyah.(2012).Pengarauh Pendidikan Kesehatan Terhadap Perilaku Diet Rendah Garam Pada Pasien Hipertensi.

Wenas Ripca Aprisilia, Anita Lontaan, Berthina H.K.(2014).Pengaruh Promosi Kesehatan Tentang Tanda Bahaya Kehamilan Terhadap Pengetahuan Ibu Hamil Di Puskesmas Amurang Kabupaten Minahasa Selatan.JIDAN vol 2 no 2 juli-desember 2014.

WHO, 2018. Angka Kematian Ibu. http://www.who.int/gho/maternal health/mortality/maternal mortality text/en/. Diakses 1 Februari 2018

Winkjosastro, Hanita, 2015. Ilmu Kebidanan, Yayasan Bina Pustaka Sarwono Prawirohardjo, Jakarta

Yanti, 2016. Hubungan Antara Pengetahuan Ibu Hamil Tentang Tanda Bahaya dan Komplikasi 


UUNнA]

